in an adult, as instanced in several of the cases quoted, is very remarkable.

The solution used in the cases reported is iodine in sesame oil, one to forty. Ten minims are injected once a week, occasionally twice. If injection is made into the skin an induration results, which will last a long time, but causes no inconvenience. If into the subcutaneous tissue there is usually nothing noticeable after a week; intramuscular injection would probably cause more severe reaction, but it has not been used by the writer. Occasionally sharp local reactions develop, or the effect may be felt all through a limb, but this quickly subsides.

The results obtained from the routine use of iodine in iritis and tuberculosis of the eye, quite apart from those obtained by the writer in a large number of other cases, aftord more than sufficient evidence of the great usefulness of this method of using the drug. The fact that it is injected hypodermically, and thus acts constitutionally, indicates that its use may be greatly extended, and it has already proved a most useful remedy in the hands of the general practitioner.

\title{
NOTE ON AN EARLY CASE OF MULES'S OPERATION
}

\author{
BY \\ HAROLD GRIMSDALE, \\ LONDON.
}

THE statement sometimes made that the globe in Mules's operation always eventually escapes, suggests the publication of the following note :

Mary D. was admitted into St. George's Hospital under the care of the late Mr. R. Brudenell Carter, on August 24, 1888, on account of a painful blind eye. The cause of the blindness is stated to have been iridocyclitis.

Three days later Mr. Carter performed Mules's operation. The wound was closed by a single layer of sutures; the line of closure was horizontal. The course of healing was uneventful, according to the notes, and the patient left the hospital with the glass globe well covered.

She came to St. George's Hospital on July 12, 1919-almost 31 years after the operation-for glasses for the right eye. Recognizing from the appearance that the original operation probably had been Mules's, I made enquiries and was able readily to find the original notes.

The stump is well covered; the globe with the enclosing sclerotic is about $15 \mathrm{~mm}$. in diameter and the movements are very good. She has always worn a glass shell eye without trouble. 